\title{
Book Review: In a Different Key: The Story of Autism
}

\author{
Geon Ho Bahn \\ Department of Psychiatry, Kyung Hee University School of Medicine, Seoul, Korea
}

\section{서평: In a Different Key: The Story of Autism}

반 건 호

경희대학교 의학전문대학원 정신건강의학과

Received: December 15, 2016 / Revision: December 16, 2016 / Accepted: December 16, 2016

Address for correspondence: Geon Ho Bahn, Department of Psychiatry, Kyung Hee University School of Medicine, 26 Kyunghee-daero, Dongdaemun-gu, Seoul 02447, Korea

Tel: +82-2-958-8556, Fax: +82-2-957-1997, E-mail: mompeian@khu.ac.kr

John Donovan and Caren Zucker

Crown Publishers: New York; 2016

ISBN: 978-0-307-98567-5

자폐증의 발병 원인은 물론 치료법에 대해서 아직 명확하 게 밝혀진 것이 없다. 1960 년대에는 아주 드물게 발생하는 병 이라고 알려져 있었으나, 최근 유병률이 조현병보다 높은 $1 / 86$ 로 발표되었다. 정신과 또는 소아과 의사들은 의료 현장에 서 만나는 자폐증 아동이나 가족들이 부담스럽기도 하다. 그러 는 사이 오히려 의료계 밖에서 자폐증에 대해 관심을 더 갖게 된 것은 당연한 결과인지도 모른다. 'In a different key: the story of autism'은 불과 1970 1980년 동안 자폐증과 관련되 어 일어났던 불행한 사건들, 용감한 부모들, 과학을 표방한 무 지한 행위들, 희망을 잃지 않는 자폐인 가족들, 그리고 자폐증 과 관련된 여러 일들을 비의료인의 시각에서 담백하게 기술 하였다. 올 초 뉴욕타임즈 기사에서 이 책의 출간 기사를 보면 서 자폐증에 대해 비의료인이 600쪽이 넘는 책을 썼다는 점에 서 호기심이 생겼고, 아마존에서 제공하는 몇 쪽의 맛보기 내 용을 보면서 갑자기 우물 밖으로 튕겨져 나온 개구리처럼 깜 짝 놀랐다. 소아정신과 의사로서 알고 있었던 자폐 관련 지식 이 정말 한 줌이었다는 사실과, 이 책이 소개하고 있는 태평양 처럼 넓고 깊은 자폐의 역사를 모르고 있었다는 사실에 당황 하기도 했다. 10부 46장으로 구성된 이 책의 내용은 매우 방 대하여 이번 지면을 통해 소개하는 것이 쉽지 않았고, 일부 내 용에 대해서만 소개하고자 한다.

This is an Open Access article distributed under the terms of the Creative Commons Attribution Non-Commercial License (http://creativecommons.org/licenses/by-nc/3.0) which permits unrestricted non-commercial use, distribution, and reproduction in any medium, provided the original work is properly cited.

\section{1부 Autism’s First Child(1930 1960년대)}

오늘날 자폐증이라고 불리는 진단개념을 처음으로 도입한 Leo Kanner라는 인물 소개와 그가 만난 최초의 자폐아동들 에 대한 내용을 소개한다. 과거 역사 속의 자폐인이라고 생각 되는 인물들에 대한 소개도 있다. 예를 들면 1469년경 러시아 에서 태어난 Basil이라는 구두장이, 18세기 스코틀랜드 Borgue 지방에 살았던 Hugh Blair, 19세기 초 프랑스 아비뇽 숲에서 발견된 야생소년 등에 대한 이야기이다.

Leo Kanner는 독일에서 태어났고, 일차세계대전 때 독일 군에 지원했다가 작은 키와 앞니가 빠져 있는 신체문제로 입대 가 거부되었다. 대신 오스트리아 군에 입대하여 전쟁에 참가 하였으며, 전쟁 후 베를린으로 돌아가 의과대학을 다녔다. 결 혼하여 자녀를 갖게 된 Kanner 부부는 미국이라는 신세계를 동경하여 이민비자를 신청한다. Kanner는 당시 7개 국어를 구사하였으나, 안타깝게도 영어는 전혀 하지 못했다. 아무튼 1928년 미국 Baltimore에 도착한 그는 Johns Hopkins 대학 의 정신과 수장인 Adolf Meyer 휘하에서 2년간 전임의 과정 을 마친 뒤, 동 대학병원에 최초로 소아정신과를 개설하였다. 이후 소아정신과 교과서를 발간하는 등 1930년대 중반에는 미 국은 물론 세계적으로도 유명한 소아정신과 의사가 되었다.

1933년 9월 9일 미시시피 주 시골에서 Donald Triplett라는 남자아이가 태어났다. 아이는 자기 부모는 물론 외부 세상에 대해 전혀 아무 관심이 없었다. 부모는 아들의 문제가 무엇인 지 알기 위해 용하다는 의사들은 다 찾아다녔다. 하지만 누구 도 답을 주지 못했다. 마침내 아이의 아버지는 당시 유명한 소 아정신과 의사로 알려진 Leo Kanner를 만나기 위해 자기 아 
들의 기이한 행동을 기술한 33쪽의 긴 편지를 보냈고, 1938년 아이의 부모는 미시시피에서 산넘고 물건너 Baltimore로 찾 아갔다. 마침내 다섯 살짜리 Donald와 Leo Kanner가 만나게 된다. 이후 그들은 편지를 주고 받으며 아이의 상태에 대하여 상의한다. 그리하여 Donald는 Kanner 박사의 첫 자폐환자가 된다.

\section{2부 The Blame Game(1960 1980년대)}

1948년 4월 26일자 타임지에 ‘의학: 얼어붙은 아이들이라는 기사가 실린다. 이 당시 자폐증에 대한 정확한 지식이 없을 때 이며, 이 기사의 대상이 되는 아이들은 소위 '기저귀를 찬 분열 성 아이들로 묘사되었다. 아마도 당시 조현병에 대한 지식은 있 었고, Kanner가 'autistic disturbances with affective contacts' 라고 발표하였기에, 이 아이들에게 자폐증 대신 분열성(schizoids)이라는 용어를 사용한 듯하다. 이 기사 말미에 "아이들이 이렇게 냉장고에서 그대로 녹지 않은 채...”라는 표현은 이후 몇 십 년 동안 자폐증은 물론 자폐증 아이를 가진 부모들의 가 슴에 대못을 박게 된다.

이 냉장고라는 은유를 '냉장고 엄마(refrigerator mother)' 라는 표현으로 전파시키는 데 가장 크게 공을 세운 이는 자폐 증 역사에 길이 남을 또 한 사람인 Bruno Bettelheim(1903 1990)이다. 유능한 소아정신분석전문가, 존경 받는 육아전문 가, 심리학계의 기린아 등 그에게 붙은 수식어는 매우 다양하 다. 텔레비전 프로그램의 단골 초청인사이기도 했다. 'The empty fortress,' 'The uses of enchantment', 'The children of the dream' 등 베스트셀러의 저자이기도 하다. 그는 타임지 에 '자폐성향 있는 아이들이 냉장고 속의 녹지 않고 있는이라 는 기사 내용과 자신의 오스트리아 나치수용서 시절 경험을 연계하여 기술하였다. 즉, 나치 유태인 수용소에서 간수들의 냉혹한 태도는 죄수들을 얼어붙게 만드는데, 자폐아이들의 부 모들도 냉랭한 태도로 아이들이 자폐증이 되도록 한다는 것 이다. 즉, '냉장고 엄마가 아이를 자폐로 만든다'라는 비약이 탄생한다. 자폐아이의 엄마는 마치 나치의 간수와 같다고 세 상사람들은 받아들였다. 이후 그는 자폐관련 연구비도 받았 고, 관련된 이론들을 발표하기도 하였다.

Bettelheim은 유태인으로 비엔나 대학에서 예술사로 박사 학위를 받았으나, 의과대학을 다니거나 심리학을 전공하지는 않았다. 미국에서는 통상적으로 의과대학을 졸업했거나 심리 학 대학원을 마친 경우 'doctor'라는 호칭을 부여하는데 그는 공식적으로 그러한 과정을 거치지 않았음에도 불구하고 미국 에 정착한 뒤 'doctor'라고 불렸고, 장애가 있는 아이들을 치 료하는 일에 종사하였다. 1939년 5월 뉴욕에 도착할 당시 그
는 병들고 영어도 잘 못하는 외국인이었다. 그러한 그가 십 년 뒤인 1950년, 장애가 있는 아이들의 치료법을 개발하는 시카 고대학 ‘Sonia Shankman Orthogenic School’의 책임자로 부 임한 것은 불가사의한 일이 아닐 수 없다. 그가 유명세를 탄 이유 중의 하나는 오스트리아 Buchenwald 유태인 수용소에 있었고, 1939년 어느 날 게스타포 대위가 자신에게 외출증을 주며 며칠간 말미를 줄 테니 오스트리아를 떠나라고 했고, 이 게스타포 대위가 유태인 학살의 주범이 된 Adolf Eichmann 이었다는 것이다(Bettelheim이 유태인 수용소에 있었던 것은 사실이지만, 그가 Adolf Eichmann을 만난 내용은 훗날 거짓 으로 판명되었다).

20여 년간 냉장고 엄마 이론은 지속되었고, 1960년대 들어 Kanner는 자신의 이론이 틀렸음을 인정하였고, 자폐증은 뇌 의 병변이라고 보고하였다.

20세기 초 수용시설에 갇힌(오늘날의) 자폐증 아이들이 평생 을 그곳에서 보내고 있는 동안, 자폐증이라는 진단은 모르지 만 자신의 아이가 남과 다르다는 것을 인식하기 시작한 부모 들은 의사에게 진단을 받는다고 해도 해결책이 없음을 알게 되었다. 자폐아이가 있는 부모들 사회에서 '성인'으로 불리는 Bernard Rimland 역시 그런 부모 중 하나였다. 문맹인 러시 아 이민자 가정에서 태어난 그는 공부를 왜 하느냐는 부모의 반대를 무릅쓰고 자력으로 샌디에고 주립대학에서 심리학을 공부하고, 펜실베니아 주립대학에서 박사학위를 받는다. 그 후 결혼도 하고 좋은 직장에 취직도 했다. 1956년 아들 Mark 가 태어났다. 하지만 아이가 크면서 '엄마', '아빠’도 말하지 않 고 이상하다는 것을 느꼈고, 결국 그 상태가 '자폐증'이라는 것을 알게 된다. 당시 사회에는 Bettelheim 박사가 주장하는 자폐증 엄마가 '냉장고 엄마'라는 이론이 지배적이었다. 자신 이 심리학박사인 Rimland로서 그 이론이 근거도 없고 확인되 지 않은 사실이라는 것을 알게 되었다. 그는 아내인 Gloria가 '냉장고 엄마가 아니라고 알고 있었으나, 학문적으로 대응하기 위해 다른 자폐부모들의 의견을 모으기 시작했다.

루이지애나 서부에 살고 있는 Ruth Sullivan은 영어학부 교 수의 부인이었다. 공중보건 석사학위가 있는 육군 간호사 출 신이기도 한 그녀는 자신의 아들 Joe가 자폐진단을 받은 뒤 읽 은 논문에서 자폐아동은 '냉정한' 엄마에 의해 생겨난 것이라 는 것을 읽고 경악을 금치 못한다. 이후 의학적 논문과 자료들 을 검토하기 시작한다. .

부모들은 서로 연락을 시작하였고, 마침내 1965년 11월 14 일, 뉴저지 주, Teaneck이라는 도시의 한 가정집에서 모임을 갖 고 National Society for Autistic Children(NSAC)이라는 단 체를 결정한다. 워싱턴 DC에서 온 쌍둥이 자폐증 여자애들의 엄마인 Mooza Grant를 초대 회장으로 선출한다. 


\section{3부 The end of Institutions(1970 1990년대)}

Archibald Casto는 1913년 2월 17일 웨스트 버지니아의 헌팅 톤에서 Casto 부부의 넷째 아이로 태어났다. 유난히 아름다운 용모를 가진 사내아이였으나 걸어다니면서부터 불 속에 뛰어 든다든가, 천둥벼락이 치는 데도 밖에 나가려 하는 등 위험한 것을 인식하지 못하고 부모가 불러도 쳐다보지도 않았다. 세 살이 지나도 말을 하지 못했고, 부모는 아이가 귀머거리가 아닌 가 생각한다. 다섯 돌이 되는 해 부모는 아이를 의사에게 데려 갔고, 의사는 아이가 "미쳤다(insane)"고 선언하였다. 당시 사회 에서는 정신적으로 문제가 있거나 간질이 있는 경우 사회에서 격리시키는 분위기였다. Archibald의 부모도 주에서 합법적 으로 지정된 정신병원에 입원시켰고, 이후 평생 죽을 때까지 수용소와 병원에서 지냈다. 이곳은 말이 병원이지 육체적 및 성적 학대와 폭행, 비위생적 환경이 판을 치는 곳이었다. 제2 차 세계대전에 참전하는 대신 정신병원에서 일하도록 한 양심 적 병역 거부자들이 수용시설에서 목격한 잔악한 행위에 대 해 사진을 찍어 외부에 알렸고, 국민들은 충격을 받았다. 이들 사진 일부는 Life 지에 실리기도 하였다. 그럼에도 불구하고 이들의 시설은 폐쇄되거나 조사받지도 않았고 계속 유지되었 다. 1960 1970년대 용감한 기자들이 이러한 수용시설에 잠입 하여 실태를 폭로하면서 한두 개씩 폐쇄되기 시작하였다. 1918년부터 이러한 시설에 수용된 Archibald 본인은 물론 가족 들도 그가 자폐증이라는 것을 알지 못한 채, 1960년대 어느 날 인근 스펜서 병원으로 옮겨졌고, 이후 가족들은 그의 소식을 들을 수 없었다. 그러나 누나인 Harriet과 NSAC의 Ruth Sullivan 박사의 도움을 받아 삼천 여명을 수용하고 있던 병원을 나와 다섯 명이 함께 지내는 그룹 홈에서 살게 되었다. 81세가 된 1995년 어느 날 North Carolina의 바닷가에 그룹홈 식구들 과 소풍을 갔고, 평생 처음으로 바다를 보았다. 1997년 83세에 사망하였다. 살아있는 동안 그는 최고령 자폐증 환자였다.

\section{4부 Behavior, Analyzed(1950 1990년대)}

1950년 미국 아이오와 주 Luther College에 음악 장학생으 로 유학온 노르웨이 출신 음악도인 Ivar Lovaas는 심리학이 라는 학문에 매료되어 1960년대 초 UCLA의 자폐아동을 위 한 LSD 치료 연구팀에 합류한다. 이후 자폐아이들의 행동문 제를 조절하기 위한 여러 가지 기법 연구에 참여한다. 새로운 치료 기법에는 전기충격요법도 포함된다. 그는 자폐증 환아의 행동조절에 ‘처벌(punishment)'이 유용한 방법이라고 생각했 다. 그의 행동주의 치료 기법은 인도적 차원에서 많은 비난을 받기도 하였으나, 자폐증 아이가 있는 집의 부모나 가족들은
그렇게 해서라도 환아의 행동문제를 조절하기를 원했다.

이러한 행동주의 원리는 1964년 학술지 'Behavior research and therapy'에 발표된 'Dicky Study'에 반영되었다. 즉, 디키 라고 불리던 세 살짜리 자폐환아의 자해 행동과 공격성을 줄 여주기 위해 사용한 'applied behavior analysis'이다.

\section{5부 The Questions Asked in London (1960 1990년대)}

자폐증에 대한 관심이 늘면서 실제로 얼마나 많은 아이들이 자폐증에 걸리는가, 즉, 유병률에 대한 관심이 생겨났다. 남아 프리카공화국에서 태어나 케이프타운대학에서 심리학을 전 공한 Victor Lotter도 그중 한 명이었다. 강직성척추염 때문에 뒤늦게 학업을 시작한 그는 대학 졸업 후 영국 모슬리병원에 서 일하던 호주출신 Neil O’Connor에게서 일자리를 제공받 아 1963년 런던으로 왔다. 그가 담당해야 하는 일은 Middlesex County의 자폐증 역학 연구였다. 대규모 집단을 확보하기 위해 그는 1953년부터 1955년 사이에 출생한 그 지역 8 10세 아이들 78000 명을 대상으로 삼았다. 좋은 자료를 확보하기 위 해 그는 그 많은 대상을 한 명씩, 한 가정씩, 직접 방문하여 만 나기 시작하였다. 그 작업도 힘든 과정이었으나, 새로운 암초 에 부딪친다. 자폐증이라는 진단을 어떻게 내려야 하는가 하 는 것이었다. 용어 자체도 천차만별이었다. Leo Kanner의 'infantile autism', Beata Rank의 'atypical child', Margaret Mahler 의 'symbiotic psychosis', 그 외 'schizophrenic psychosis of childhood', 'dementia praecocissima', 'dementia infantilis', 'prepubertal schizophrenia', 'latent schizophrenia' 등이 혼 용되고 있었다. Lotter는 이러한 개념들을 분석하여 '대부분 의 시간을 혼자 보낸다, 이상한 물건을 수집한다, 독특한 또 는 특별한 소리를 낸다, 몸동작이 어색하다, 물건을 괴상한 방 법(냄새를 맡거나 깨물기)으로 탐색한다' 등 22 개의 문항을 개발하여, 면접에 사용하기 시작하였다. 그는 자신의 22 문항 짜리 설문을 지역 교사들에게 발송하여 설문 내용상 자폐증 으로 의심되는 아이들을 추천해주도록 부탁하였다. 그 결과 78000 명의 대상 아동 중 666 명의 의심군 목록이 작성되었다. 의심군을 좀 더 세분화하여 분석한 결과 88 명이 고위험군으 로 분류되었다. 그 밖에 학교가 아닌 정부의료기관에서 의뢰된 47명을 포함, 총 135 명을 연구 대상으로 결정하였다. Lotter의 아내인 Ann 역시 심리학자였으며, 그의 연구를 도왔다. 부부 는 이 아이들을 만나기 위하여 학교, 병원 등으로 찾아갔고, 지능과 언어를 평가, 아이들을 가장 잘 아는 인물과 면담도 진 행하였다. 1963년 가을 시작된 연구는 1966년 논문을 발표하 면서 마무리된다. 8 10세 아동 78000명 중 35명, 또는 만 명당 
4.5명이 최초의 자폐증 유병률이다.

\section{6부 Redefining a Diagnosis(1980 1990년대)}

영국에서 의과대학을 다니던 Lorna는 해부학 시간에 같은 사체 실습조였던 John Wing과 결혼하였고, 1956년 딸 Susie 를 낳았다. 딸이 세 살이 될 무렵, 부부는 아이가 다른 아이들 과 다르다는 것을 알게 되었고, 당시 그런 아이를 자폐증이라 고 진단한다는 것을 처음으로 알게 되었다. 이후 자폐증에 대 해 관심을 갖게 되었고, 평생 연구주제가 된다. 그녀는 이전 연구들을 통해 자폐증의 증세와 심각성이 사례별로 매우 다 르다는 것을 알게 되었고, 그러한 이유로 '자폐증'보다는 '자폐 스펙트럼이라는 개념에 대해 증명하려고 노력했다.

오스트리아 비엔나 의과대학 소아과 의사였던 Hans Asperger는 1944년 7 17세 사이의 네 명의 독특한 남자아이 사 례를 모아 61쪽짜리 논문을 출판하였다. 그는 이 아이들을 ‘Autistischen Psychopathen', 즉 ‘자폐적 정신병리’라고 명명 하였다. 그는 독일어로만 논문을 써서 발표하였기 때문에, 그 리고 이차대전 패전국 독일과 오스트리아가 공조하였기 때문 에 독일 이외의 국가에서는 Asperger 박사의 존재 자체를 알 지 못했다. 자폐스펙트럼 개념에 관심이 있던 Lorna는 남편 John이 영어로 번역해 준 Asperger의 논문을 읽게 되었고, 자폐 증에 스펙트럼 개념이 있다는 생각을 굳혔다. 그녀는 Asperger 가 발표한 1944년 사례들과 자신의 경험을 추가하여 1981년 'Asperger 증후군' 논문을 발표한다. Asperger는 1980년 74세 의 나이로 사망하였다.

1993년 DSM-IV 준비위원회 소속인 Yale Study Center의 Fred Volkmar는 한 통의 제보를 받는다. Asperger가 독일 Nazi의 협력자였다는 것이었다. Fred는 DSM-IV에 추가할 새로운 진단명 중 하나로 Asperger 증후군 진단기준을 완성 한 상태였다. 그는 급히 Asperger 증후군 전문가인 Lorna Wing에게 이 사실에 대해 확인해 줄 것을 부탁하였다. Lorna 는 펄쩍 뛰면서 즉각 부정했다. Asperger 박사는 매우 신실한 사람이라는 것이다. 몇 달 후, 1994년 발표된 DSM-IV에 Asperger 증후군이라는 새로운 진단명이 등재되었다. Asperger 의 딸이며 정신과 의사인 Maria Asperger는 자기 아버지가 Nazi의 인종주의에 반대했고, 고통받는 아이들을 돕고자 했 으며, 항상 모든 살아있는 생물에 대해 흥미와 관심을 보였다 고 발표한 바 있다. 하지만, 2010년 5월 비엔나 시청에서 Hans Asperger와 그의 업적을 기념하는 행사가 열렸을 때, 나치가 유럽을 점령하던 시절 의학의 역할에 대한 전문가인 Herwig Czech가 연사로 초청받았다. 그의 강연 제목은 '비엔나의 나 치 아동 안락사 프로그램과 Hans Asperger 박사-연결고리의
가능성'이었다. 그 강연에서 Asperger 박사가 알려진 것보다 더 나치 정권과 가깝게 지냈다는 서류가 발견되었다.

\section{7부 Dreams and Boundaries(1980 1990년대)}

1980년대 자폐증 환자가 말을 하지 못하더라도 타자기로 자 기 의사를 정확히 알릴 수 있다는 'facilitated communication' $(\mathrm{FC})$ 이라는 기법이 등장하였다. 보조자가 환자 옆에 앉아 환자 가 가리키는 타이핑을 하면 환자가 정확한 의사를 표현하기 도 한다는 것이었다. 이 방법은 많은 환자 가족들에게 희망을 불어넣어 주었다. Betsy라는 자폐아동과 함께 작업했던 Janyce Boynton은 Betsy가 FC를 통해 자기 의사를 정확하게 문장으로 구사하는 것을 느꼈다. 하지만 간단한 실험을 통해 실제로는 베씨가 타자기로 자신의 의사를 표현한다기보다는 자기도 모르게 Boynton이 정확한 답을 골라낸 것일 수 있음 이 밝혀졌다.

\section{8부 How Autism Became Famous (1980 1990년대)}

1988년 12월 개봉된 영화 'Rain Man'은 자폐증에 대한 최초 의 좋은 영화였다. 영화 제작 당시 생존해 있었던 Kim Peek이 라는 기억력이 뛰어난 유명한 미국의 자폐환자에 대한 이야기 를 바탕으로 한 것이었다. 2010년 영화 ‘Temple Grandin'이 극 장가에서 개봉하였다. Claire Danes 주연이었다. 같은 해 2월 에미상 시상식에서 이 영화는 7개 부문을 석권한다. 영화제작 자로서 수상하게 된 Gerson Saines는 수상 소감에서 "자폐증 이 전염병(epidemic) 수준이에요.”라고 하였다(영화 ‘Rain Man' 에 이어 'Temple Grandin'까지 자폐증에 대한 좋은 사회문화 적 분위기가 확산된다는 의미).

\section{9부 ‘Epidemic'(1990 2010년대)}

자폐증에 대한 관심이 늘어나면서 원인에 대한 궁금증도 커 져갔다. 마침내 그 답을 찾아냈다고 주장한 의사가 등장하였 다. 영국 런던 Royal Free Hospital의 젊은 소화기내과 의사인 Andrew Wakefield는 12명의 자폐아동에게서 장내 염증을 발견하였고, 모두 홍역 바이러스와 관련이 있었다고 하였다. 이 를 토대로 자폐증이 MMR 예방접종에 의해 발병할 수 있다 고 주장하였다. 이 내용은 영국의 가장 오래된 의학잡지이자 전 세계적으로 가장 인정받고 있는 Lancet에 1998년 2월 26 일자로 게재되었다. 이후 영국에서 예방접종률이 떨어지기 시 작하였고, 자신의 아이도 예방접종 후 자폐증이 생겼다고 주장 
하는 부모가 늘기 시작하였다. 설상가상으로 새로운 가설이 등장한다. 2000년 6월, 미국 조지아 주 간호사 출신인 Lyn Redwood의 주장이 세간의 주목을 끌었다. 그녀는 자기 아들 Will이 건강하고 밝게 잘 자랐는데 돌 지날 무렵 예방접종을 맞고 나서부터 변했다고 하였다. 그러나 그녀는 MMR보다는 예방접종에 사용하는 주사제의 수은이 주범이라고 하였다.

이러한 애매한 가설들이 난무하는 가운데 2005년 2월 미 국 $\mathrm{NBC}$ 에서 약 4 개월 동안 아침과 저녁 뉴스 시간마다 잠깐 씩 'Autism: the hidden epidemic'이라는 주제를 방영하였다. 수천만 명의 시청자가 이 프로그램에 관심을 가졌다. 마지막 방송에서 $\mathrm{NBC} \mathrm{CEO}$ 인 Bob Wright는 "자폐증 환자 가족은 대부분 탈진하고 망가진다.”고 하였다. 이어 그의 아내인 Suzanne는 "자폐에 관한 훌륭한 조직들이 있지만 사적인 단체들 이라서, 국가적 조직이 필요하다”면서 자기 윗도리 한 편에 달 려 있는 푸른색 퍼즐 조각 모양을 가리켰다. 이 로고는 몇 달 후에 발족된 'Autism Speaks'라는 단체의 상징이 되었다. 이 단체는 이전 단체들이 환자 부모들 위주의 소규모로 운영되 는 것과는 차원이 달랐다. 환자 가족은 물론 의사, 정치가, 재 벌총수 등이 회원으로 가입하였고, 정부로부터 엄청난 연구 비를 지원받게 되었다. 2006년 'The Combating Autism Act' 가 제정되면서 수조원의 정부자금이 자폐증 연구에 투입되기 시작하면서, 전 세계 연구자들이 자폐 연구에 지원하게 되는 전기를 마련하게 되었다.

한편, 영국 Sunday Times의 취재기자인 Brian Deer는 과학 계에서 Wakefield의 논문과 주장에 대해 반박하는 것에 주 목하였다. 그는 Wakefield의 논문에 등장하는 12 명의 환자와 그 가족을 취재하기 시작하였다. 그 과정에서 Wakefield의 연 구 과정에 윤리적 문제와 비과학적 논리가 상당부분 포함되 어 있음을 알게 되었다. 기자가 처음 만난 사례의 부모는 예방 접종 후 아이에게서 이상 증세를 느끼기 시작한 것은 몇 달이 지난 뒤라고 하였다. Wakefield는 예방접종 후 14 일 이내에 부모가 증상을 감지하였다고 보고하였었다. 또한 MMR 제조 업체와의 소송을 준비하는 변호사와 Wakefield가 연관되어 있으며, Wakefield가 예비 연구를 위한 자금으로 8 만불을 받 았다는 사실이 드러났다. 이 8 만불로 진행한 연구결과가 바로 Lancet 지에 실린 논문이었다. 게다가 Wakefield는 연구결과 가 학술지에 실리기도 전에 그 결과를 변호사에게 전해 준 것 으로 드러났다. 이에 대해 Wakefield는 자신은 어떠한 범법행 위나 윤리규정을 위반하지 않았으며, 사소한 실수가 있었을 뿐 이라고 주장하였다. Lancet의 편집장도 Wakefield가 "conflict of interest'에 대해 명확히 밝히지 않으면, 논문 게재를 철회 할 것이라고 하였으며, 보건당국도 지대한 관심을 갖게 되었 다. 그간 Wakefield를 옹호하던 언론도 Wakefield를 비난하
는 기사를 내보냈다. 그럼에도 불구하고 일부 언론에서는 여 전히 자폐에 대한 의문이 풀리기 전까지는 $\mathrm{MMR}$ 접종을 미 뤄야 된다고 보도하였다. 결국 $\mathrm{MMR}$ 에 대한 공포는 지속되고 그의 추종자들은 여전히 그를 지지했다. Wakefield도 결코 주춤하지 않았고, Deer의 주장은 제약회사들의 음모라고 맞 받아쳤다. 음모론을 믿는 사람들은 제약회사와 의학 전문가 들이 연결되어 있으며, 야망과 돈을 위해 진실을 숨기고 있다 고 생각했다. 이것이 과학계가 백신이론을 밝히는데 실패하는 이유라고 생각했으며, 관련 정부기관들도 이러한 부패의 고리 에 연결되어 있다고 믿었다. 그러나 후속 연구들이 MMR 백 신과 자폐증이 어떠한 관련도 없음을 밝혀냈으며, Wakefield 의 연구 자체에 문제가 있음이 드러났다.

2009년 2월 12일, 백신 접종 후 자폐가 발생하였다고 주장 하는 Michelle Cedillo의 보상에 관한 재판 판결이 나왔다. 재 판부는 Michelle의 자폐증이 MMR을 비롯한 다른 백신과 연 관이 없다(extremely unlikely)고 판결하였다. 2010년 1월 28일 자폐증과 MMR 접종과의 관련성을 보고한 영국의사 Andrew Wakefield의 "정직하지 못하고, 책임감이 없으며, 비윤리적이 고, 오해의 소지가 있는” 행동에 대해 유죄를 선고하였다. 같은 해 2월, Lancet 지는 1998년도에 게재된 그의 논문을 철회하 였고, 5 월 영국 의사 면허를 취소당했다. 타임지는 역사상 '최 대 과학 사기꾼' 중 1순위로 Andrew Wakefield를 꼽았다.

\section{0부 Today}

2013년 9월, Mississipi Forest의 아트 갤러리에서 Donald Triplett의 가족과 친구들이 모였다. Donald는 Leo Kanner 박 사의 첫 자폐환아였다. 그날은 Donald의 80세 생일을 축하하 는 자리였다. 그는 친구들과 지역주민들의 돌봄과 도움을 받 으며 학교에 다닐 수 있었고, East Central Community College 에 입학해서 2년 만에 졸업했고, Millsaps College에 진학하여 불어를 전공하였다. 27세가 되던 1960년, 평생 스승인 어머니 로부터 운전을 배웠다. 학교를 졸업한 뒤 고향으로 돌아와 가 족이 운영하는 은행에서 창구업무를 담당했다. 심각한 실수 를 자주 했지만 가족과 지역주민들 모두 그를 이해해주었다. 은행이 경영난 때문에 다른 이에게 넘어갔지만 새 주인은 그 에게 계속 은행에서 일하도록 해 주었고, 새로 온 직원들에게 는 그가 어떤 특징을 가지고 있는지, 그리고 어떻게 대해야 하 는지 설명해주었다. 그는 그렇게 존중 받는 인물이 되었다. 70 대가 되면서 그는 '은퇴'하였지만, 아직까지도 매일 은행에 들 르고 있다. 은행 사람들은 그의 식구나 다름없기 때문이다.

1956년에 Donald는 골프를 배우기 시작했고, 푹 빠졌다. 그 후 골프는 평생 그의 동반자가 되었다. 골프를 칠 때마다 
독특한 습관과 행동을 반복했지만 지역주민들 모두 그를 알 고 있었고, 이해해주었다. 79 세가 되던 해 친지의 권유로 핸드 폰을 접하게 되었고, 문자메시지 보내는 것에 푹 빠져들었다. 아래 내용은 그가 친구에게 보낸 문자메시지이다.

Donald: See u on June 16.

Celeste: Have fun and be careful Don!!

Donald: I shoot u with a rubber band Sunday.

그의 아버지가 차 사고로 사망하고, 그로부터 5년 뒤 어머 니도 심부전으로 돌아가셨다. 두 번의 장례식에서 그는 감정 변화를 나타내지 않았다. 어머니가 돌아가셨을 때 심정을 묻 자 "어느 정도 예상했던 일이고, 크게 상심하거나 울지 않아
요.”라고 대답하였다.

80세 생일 파티 내내 웃음을 띠고 있지만 평소처럼 별 말 이 없었다. 그저 "내가 80살이 돼서 기뻐요." 정도였다. 자폐진 단을 받은 최초의 인물이기도 한 Donald는 작은 고향마을에 서 행복하게 살았고, 남은 삶도 골프를 즐기며 살아갈 것이다.

\section{맺는 말}

현존하는 가장 많이 알려진 자폐인 중의 한 사람이자 가장 뛰어난 과학자의 한 사람인 Temple Grandin의 서평이 이 책 의 가치를 말해준다. "이 책은 독자들을 자폐증의 초창기 과 거로 돌아가게 해준다. 자신과 '다른' 사람들을 사회가 어떻게 취급하는지 관심 있는 사람이라면 꼭 읽어야 하는 책이다." 